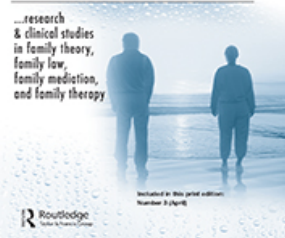

\title{
Psychological Morbidity, Social Intimacy, Physical Symptomatology, and Lifestyle in Adult Children of Divorced Parents
}

\section{Fabrícia Colen \& M. Graça Pereira}

To cite this article: Fabrícia Colen \& M. Graça Pereira (2019) Psychological Morbidity, Social Intimacy, Physical Symptomatology, and Lifestyle in Adult Children of Divorced Parents, Journal of Divorce \& Remarriage, 60:3, 183-193, DOI: 10.1080/10502556.2018.1488118

To link to this article: https://doi.org/10.1080/10502556.2018.1488118

\section{Published online: 20 Jul 2018.}

Submit your article to this journal

LلI Article views: 888

Q View related articles $\sqsubset$

View Crossmark data \lceil 


\title{
Psychological Morbidity, Social Intimacy, Physical Symptomatology, and Lifestyle in Adult Children of Divorced Parents
}

\author{
Fabrícia Colen and M. Graça Pereira (1) \\ School of Psychology, University of Minho, Braga, Portugal
}

\begin{abstract}
This study assessed the relationships between psychological morbidity, social intimacy, perception of the parental relationship, lifestyle and physical symptomatology as well as the contributors of physical symptomatology, in adult children of divorced parents. Participants answered the Physical Symptom Questionnaire, the Anxiety, Depression and Stress Scale, the Lifestyle Questionnaire, the Social Intimacy Scale and The Perception of the Parental Relationship Scale. Results revealed that older participants showed lower levels of anxiety, depression and stress and that male participants perceived the parental relationship as better when compared to females. There was a negative association between depression and the duration of parental divorce. Adult children with greater physical symptoms and more anxious showed less social intimacy. The latter was associated with a less healthy lifestyle. As expected less physical symptomatology was associated with lower levels of depression, anxiety, and stress. Anxiety was the only variable that contributed to physical symptomatology. Intervention should be gender sensitive and focus early on on the identification of psychological morbidity, social intimacy, healthy behaviors, and physical symptomatology, in adult children whose parents are in the process of divorcing.
\end{abstract}

\section{KEYWORDS}

Adult children; divorce; psychological health; physical symptoms

Divorce and its repercussions in childhood and adolescence have been the frequent focus of research since this change in family dynamics may impact the physical and psychological health of children even in the beginning of their adult life (Sourander \& Helstelä, 2005; Thomas \& Högnäs, 2015).

According to Storken, Roysamb, Moum, and Tambs (2005), in a longitudinal prospective study, parental divorce was associated with changes in anxiety, depression, subjective well-being, self-esteem, and school problems, and its effect was partially mediated by paternal absence. According to $\mathrm{Yu}$, Petit, Lansford, Dodge, and Bates (2010), also in a longitudinal study, parental conflicts in children were associated with poor quality in the parent-adult relationship and divorce mediated the relationship between marital conflict and negativity in mother-child relationships, particularly in women. In addition, the level of marital conflict is a 
significant factor in children's adaptation to divorce and their mental health is associated with the quality of the parental relationship (Frankel, Umemura, Jacobvitz, \& Hazen, 2015; cf. Nunes-Costa, Lamela, \& Figueiredo, 2009). Thus, children might be at risk if the family experience is based on a difficult parental relationship, whether associated with divorce or not.

Zavaschi and colleagues (2002), and Shafer, Jensen, and Holmes (2017) showed that being deprived of one parent due to divorce might be a traumatic experience, being an important factor associated with depression, in adulthood. Other studies have shown that in addition to depression, children of divorced parents might experience irritability, poor school performance, adjustment and interpersonal relationships problems, as well as anger and anxiety (Anthony, DiPerna, \& Amato, 2014; Motataianu, 2015).

In a longitudinal comparative study by Storken et al. (2005), the authors concluded that the absence of the father triggered high levels of anxiety and depression in female adolescents aged 14 to 18, whereas male adolescents presented, above all, school issues. Anderson (2014), in a review of the literature, also suggested the presence of interpersonal problems, delinquent behavior, and depression when there was only single-parent contact.

Divorce has an impact on psychological well-being in young adults, triggering emotional problems such as depression, anxiety, and low self-esteem, among others (Fagan \& Churchill, 2012). In fact, divorce could be considered a source of acute or chronic stress with implications in long-term physical and psychological health (Fagan \& Churchill, 2012). Thormann (2000) and NunesCosta and colleagues (2009) found that somatic symptoms in children after their parents' divorce were frequent and could become constant if they ocurred in childhood. El-Sheikh, Hinnant, and Erath (2011) argued that psychological morbidity and conflicts might trigger physical symptoms.

Divorce is also considered a traumatic event. In fact, 10 years after divorce, welladjusted young college adults report a continuing sense of pain and distress about their parents' divorce (Ahrons, 2007; Kelly \& Emery, 2003). Rheingold, Acierno, and Resnick (2004), and Ahrons (2007) found that exposure to traumatic events and adverse experiences in childhood, together with the consequent psychological symptomatology, could trigger the development of health risk behaviors. In fact, in adolescents who have experienced parental divorce, there is a higher frequency of substance use, inappropriate sexual and delinquent behavior, as well as more depression, and decreased school performance (Fagan \& Churchill, 2012; NunesCosta et al., 2009; Potter, 2010).

Divorce also seems to hamper romantic relationships in young adults (Rhoades, Stanley, Markman, \& Ragan, 2012), particularly in women with less confidence and satisfaction in romantic relationships (see Fagan \& Churchill, 2012; Simon \& Barrett, 2010). According to Souza (2000), adolescents who experienced divorce might experience solitude, social isolation, or inability to seek support within their social networks. Charlish (2001) also found that the 
main symptoms of parental divorce were the fear of being abandoned, becoming less confident in personal relationships, showing little emotional investment in intimate relationships, self-confidence issues, and impaired self-esteem.

Studies on how parental relationship, social intimacy, psychological morbidity, and lifestyle relate to physical symptoms in adult children of divorced parents is scarce. This study aimed to study the relationship among those variables and which contribute most to physical symptoms in adult children of divorced parents.

\section{Method}

\section{Participants}

The sample included 75 students from a Portuguese university, adult children of divorced parents, age 18 to 25 years old, with a mean age of $21(S D=1.94)$. From the total sample, $58.7 \%$ were female. All participants were single, but $42.7 \%$ were in a romantic relationship. Only $8 \%$ reported having received psychological counseling after their parents' divorce. From the total sample, $27 \%$ reported the divorce occurred 10 to 12 years ago, $21 \%$ within 1 to 3 years ago, and in $24 \% 4$ to 6 years ago.

\section{Procedure}

Students from several university majors were invited to participate via e-mail after approval of the review board of the University's dean. Inclusion criteria included having parents who had divorced during the participant's childhood or adolescence. All participants were guaranteed confidentiality of their data and all signed an informed consent form. Participation was voluntary, and all questionnaires were completed in the university's library in the presence of the researcher.

\section{Instruments}

\section{Physical Symptom Questionnaire}

The original version by Proctor and collaborators (1998) consists of 52 items that assess how many times often the physical symptoms were experienced in the previous 30 days, in veterans of the Gulf War. The adapted version by Pereira and Pedras (2008) included 24 items that describe a list of physical symptoms distributed across the nine body systems (e.g., headaches, dizziness or feeling dizzy, gasping breathing, difficulty breathing or tachycardia). For each of the symptoms there is a 5-point Likert scale ranging from 0 (never) to 4 (almost always) that allows assessment of the frequency of the symptoms in the last 30 days. Higher scores indicate more physical symptoms. In this study, the alpha was 90 . 


\section{Anxiety, Depression and Stress Scale (EADS-21)}

This instrument was developed to evaluate depression, anxiety, and stress (Lovibond \& Lovibond, 1995). The Portuguese version was adapted by PaisRibeiro, Honrado, and Leal (2004) and includes these three subscales: Depression (e.g., I had difficulty taking initiative to do things), Anxiety (e.g., I had trouble breathing), and Stress (e.g., I have tended to overreact in certain situations), each containing 7 items. A high result score indicates more negative affective states. The Portuguese version presented alphas of .85 for the Depression subscale, .74 for the Anxiety subscale, and .81 for the Stress subscale (Pais-Ribeiro et al., 2004), whereas in this study, the alphas were $.85, .76$, and .83 , respectively, for the Depression, Anxiety, and Stress subscales.

\section{Lifestyle Questionnaire}

The original version by Pereira and Pedras (2009) assesses health behaviors (e.g., measuring blood pressure, doing blood tests, going to the dentist) and consists of 24 items. The first 7 items measure the frequency the health behaviors are performed on a 5-point Likert scale ranging from 1 (never or rarely) to 5 (every month). The following 12 items also measure the frequency with which health behaviors are performed, but the 5-point Likert scale changes, ranging from 0 (never) to 4 (every day). Finally, the last 5 items of the instrument measure the frequency of adopted health behaviors, through another 5-point Likert scale, ranging from 0 (never) to 4 (always). The Portuguese adapted version includes 19 items. High scores indicate a healthier lifestyle. In this study, Cronbach's alpha was .77.

\section{Social Intimacy Scale}

The original version (Miller \& Lefcourt, 1982) assesses intimacy relationships (e.g., in relation to your friend, when you have free time, how often do you choose to be with him or her alone?) through two subscales: Frequency and Intensity of Intimate Relationships. The scale consists of 22 items but 5 of these are not scored. The first 6 items, which refer to the frequency of intimacy contacts, are measured through a 5-point Likert scale ranging from 1 (very rarely) to 5 (almost always). The remaining 11 items measure the intensity of intimacy relationships and are also assessed through a 5-point scale ranging from 1 (very little) to 5 (very $m u c h$ ). In the original version, Items 5 and 17 are reversed. A high score indicates better social intimacy. The alpha in this sample was .93 .

\section{Perception of Parental Relationship Scale}

The original version (Pereira \& Araújo-Soares, 2002) assesses the parents' relationship according to the adult children's perspective, before the divorce, regarding the quality of the relationship (e.g., communication between the two 
parents, affectivity) and the frequency of conflict (e.g., frequency of heated arguments in front of the children), using a 7- point Likert scale. ranging from 1 (lowest frequency) to 7 (highest frequency). Higher scores indicate a better perception of the parental relationship. In this study the alpha was .85 .

\section{Data Analysis}

To assess the relatioships between all variables with physical and psychological symptomatology, a correlational analysis was performed. To find the variables that contributed to physical symptomatology, a linear regression (enter method) was performed. Of the sociodemographic variables introduced (age, gender, and marital status), only gender was related to physical symptoms. The psychological variables anxiety, depression, stress, and parental relationship were the ones related to the dependent variable, and were included in the model. Therefore, gender was introduced in Block 1, and anxiety, depression, stress, and parental relationship's perception were introduced in Block 2.

\section{Results}

\section{Relationship Between Age, Gender, Duration of Divorce, Parents' Socioeconomic Level, and Psychological Variables}

Age was positively associated with the perception of the parental relationship. Older participants showed a better perception of the parental relationship $(r=.285, p \leq .05)$. Additionally, age was negatively related with anxiety, depression, and stress. Thus, older participants showed lower levels of anxiety $(r=-.259, p \leq .05)$, depression $(r=-.285, p \leq .05)$, and stress $(r=-.360, p \leq .01)$.

Regarding participants' gender, there were differences in the perception of the parental relationship i.e. male participants perceived a better parental relationship $(Z=-2.08, p \leq .05)$. There were no differences in other variables. There was a significant negative association between depression and the duration of parents' divorce. Thus, participants whose parents were divorced for a longer period of time showed less depression $\left(r_{\mathrm{sp}}=-.243, p<.05\right)$. Finally, no significant differences were found according to parents' socioeconomic level.

\section{Relationship Between Parental Relationship, Psychological Morbidity, Social Intimacy, Lifestyle, and Physical Symptomatology}

Social intimacy was negatively associated with physical symptomatology and anxiety (see Table 1). Thus, participants with greater physical symptoms 
Table 1. Results of Pearson's Correlation Coefficient of Psychological Morbidity, Lifestyle, Physical Symptomatology, Parental Relationship, and Social Intimacy in Children of Divorced Parents.

\begin{tabular}{lccccccc}
\hline Variables & 1 & 2 & 3 & 4 & 5 & 6 & 7 \\
\hline 1. Anxiety & - & $.787^{* * *}$ & $.657^{* * *}$ & -.223 & $.684^{* * *}$ & -.059 & $-.280^{*}$ \\
2. Depression & & - & $.728^{* * *}$ & -.103 & $.556^{* * *}$ & -.051 & -.210 \\
3. Stress & & & - & -.175 & $.519^{* * *}$ & -.160 & -.152 \\
4. Lifestyle & & & & - & -.065 & -.163 & $.300^{* * *}$ \\
5. Physical symptoms & & & & & - & -.080 & $-.305^{*}$ \\
6. Parental relationship & & & & & & - & -006 \\
7. Social intimacy & & & & & & & - \\
${ }^{*} p<.05 .{ }^{* * *} p<.001$.
\end{tabular}

Table 2. Results From the Linear Regression of the Predictive Variables of Physical Symptoms in Children of Divorced Parents.

\begin{tabular}{lcc}
\hline & \multicolumn{1}{c}{ Predictors } & \\
\cline { 2 - 3 } Variables & Physical symptoms & \\
\hline Block 1 & \multicolumn{1}{c}{ Beta } & \\
Gender & -.170 & .145 \\
$R^{2}\left(\right.$ Adj. $\left.R^{2}\right)$ & $0.29(0.16)$ & \\
Block 2 & & .245 \\
Gender & -.107 & .709 \\
Depression & -.060 & $<.001^{* * *}$ \\
Anxiety & .637 & .351 \\
Stress & .124 & .944 \\
Parental relationship & -.006 & \\
$R^{2}$ (Adj. $\left.R^{2}\right)$ & $.482(.445)$ & \\
**** $p<.001$. & &
\end{tabular}

$(r=-.305, p<.05)$ and those who were more anxious $(r=-280, p<.05)$ showed less social intimacy. There was also a positive association between social intimacy and lifestyle. Thus, participants with less social intimacy showed a less health healthier lifestyle $(r=.300, p<.05)$.

There was a significant positive association between physical symptomatology and psychological morbidity; i.e., less physical symptomatology was associated with lower levels of depression $(r=.556, p<.001)$, anxiety $(r=.684, p<.001)$, and stress $(r=.519, p<.001)$.

Finally, social intimacy was negatively associated with anxiety and physical symptomatology i.e. participants with more anxiety $(r=-.280, p<.05)$ and greater physical symptomatology $(r=-.305, p<.05)$ reported less social intimacy.

\section{Contribution of Psychological Variables to Physical Symptomatology}

The regression analysis showed that only anxiety was associated with physical symptomatology. Results showed that greater anxiety predicted greater physical symptoms, and the model explained $44.5 \%$ of the variance (see Table 2 ). 


\section{Discussion}

Participants' age influenced the level of psychological morbidity and the perception of the parental relationship. Morbidity symptoms appear to be more intense and frequent in the first year after parental divorce (Cohen, 2002; Kelly \& Emery, 2003; Lansford et al., 2006). In this sense, the results are in agreement with the literature, since older children have the capacity to better understand the parental relationship, thus presenting lower levels of psychological morbidity.

Gender differences were found regarding the parental relationship's perception. The literature reveals that parental divorce might affect children and some studies point out that males are the least affected (Whitton, Rhoades, Stanley, \& Markman, 2008). Other studies have shown that male children of divorced parents were more likely to develop school problems, unlike female children, who revealed greater psychological morbidity (Hack \& Ramires, 2010; Storken et al., 2005). However, the literature is not consensual regarding gender differences: Risch, Jodl, and Eccles (2004) found that males were the most affected, as they had fewer models of intimacy outside the family when compared to women. Additionally, these authors suggest that these differences are common in all boys and girls, and not specific in children of divorce. In this study, there were only differences in the perception of the parental relationship, with boys having a better perception of the parental relationship than girls. This result might result from the fact that girls, when compared to boys, suffer more from the impact of divorce on their selfconfidence and reveal more sensitivity regarding the unexpected changes in family relationships that result from divorce (Jacquet \& Surra, 2001).

Several studies have shown that children of divorced parents might experience depression and anxiety. In addition, they might present adjustment difficulties to the situation and, later, problems in interpersonal relationships (e.g., Amato, 2001; Cohen, 2002; Kelly \& Emery, 2003; Wolchik et al., 2002). In fact, this study revealed the existence of a negative association between social intimacy and anxiety, as suggested by the literature. Other researchers also corroborate these claims and add that partial or total loss of direct contact with one parent leading to interpersonal difficulties (Cohen, 2002; Poussin \& Martin-Lebrun, 1999). Children of divorced parents who have higher anxiety levels may also present difficulties with social intimacy, within the family or the peer group.

There is also an association between high social intimacy and fewer physical symptoms. Despite the limited literature on this association, Cohen and Wills (1985) described the general model of social support, explaining the protective effect it has on adverse situations or in those with a high degree of stress with positive effects both emotionally and physically. The results in this study are in agreement with the literature, as the children 
of divorced parents who present poor intimacy also report more physical symptomatology. Thus, because social intimacy is a dimension of social support and parental divorce, an experience often considered adverse, the quality of social intimacy may function as a protective factor, leading to lower levels of physical symptomatology.

In addition, Steinberg (1987) concluded that adolescent children living with both parents were more likely to withstand peer pressure to engage in inappropriate behavior. In turn, adolescents from single-parent families are more likely to yield to peer pressure. This suggests that parental divorce has negative effects on the adoption of health risk behaviors. Adolescents and young adults might experience social isolation, inability to ask for support in the social network, loneliness, and such interpersonal problems may lead to less healthy lifestyles. Consequently, risk behaviors might lead to negative perceptions in affective relationships (e.g., Cummings \& Davies, 2002). According to the results, greater difficulties with social intimacy are associated with more health risk behaviors in children of divorced parents, as referenced in the literature.

Finally, anxiety was the only variable associated with physical symptoms. In fact, anxiety may be manifested through bodily discomfort and distress, among other biological and biochemical changes. Thus, the results of the present study corroborate the hypothesis that psychological morbidity, particularly anxiety in young adults, is associated with physical symptoms (Engel, 2004).

\section{Limitations}

This study has limitations that need to be acknowledged, such as the convenience sample and the fact that participants were all college students, which limits the generalization of the results. Future studies should broaden the sample by including children of divorced parents that are not college students or unmarried. Finally, the questionnaire on the perception of the parental relationship called for a retrospective evaluation, which is in itself a limitation because it is dependent on the participants' memory. The study also did not control for other negative experiences besides divorce.

\section{Conclusion}

Children of divorced parents who have a more positive perception of the parental relationship showed more health behaviors. These results are important for the early identification of problems such as psychological morbidity, in adult children, whose parents are in the process of divorcing, as associations between psychological morbidity, physical symptoms, and social intimacy were found in children of divorced parents. Early signaling may therefore prevent the development of these problems. 
Although much has been reported in the literature on the impact of divorce on children, there is still a great deal of work to be done regarding the impact of poor parental relationships on adult children. Thus, it is crucial to develop more comprehensive studies to understand how adult children can be affected by their parents' divorce. By understanding the difficulties that children face during parental divorce, intervention programs can be built to reduce psychological morbidity, that triggers physical symptoms, as well as hamper social intimacy relationships. Subsequent studies should try to understand the effects of divorce in children's coping strategies and the moderating role of social support. Furthermore, researchers should focus on studying psychological morbidity, physical symptomatology and social intimacy in children from intact families who report high conjugal conflict and compare them with children of divorced parents. The sample in this study was very homogeneous and young in age, but it would be important in future studies to take into account the duration of the parents' marriage before divorce and the phase (childhood vs. adolescence) in which the divorce happened.

\section{ORCID}

M. Graça Pereira (D) http://orcid.org/0000-0001-7987-2562

\section{References}

Ahrons, C. (2007). Family ties after divorce: Long-term implications for children. Family Process, 46(1), 53-65. doi:10.1111/famp.2007.46.issue-1

Amato, P. R. (2001). Children of divorce in the 1990s: An update of the amato and keith (1991) meta-analysis. Journal of Family Psychology, 15(3), 355-375. doi:10.1037/08933200.15.3.355

Anderson, J. (2014). The impact of family structure on the health of children: Effects of divorce. The Linacre Quarterly, 81(4), 378-387. doi:10.1179/0024363914Z.00000000087

Anthony, C. J., DiPerna, J. C., \& Amato, P. R. (2014). Divorce, approaches to learning, and children's academic achievement: A longitudinal analysis of mediated and moderated effects. Journal of School Psychology, 52(3), 249-261. doi:10.1016/j.jsp.2014.03.003

Charlish, A. (2001). Apanhados no meio: Ajudar as crianças a enfrentarem a separação e o divórcio [Caught in the middle: Helping children cope with separation and divorce]. Porto: Ambar.

Cohen, L. (2002). Helping children and families deal with divorce and separation. American Academy of Pediatrics, 110(5), 1019-1023.

Cohen, S., \& Wills, T. A. (1985). Stress, social support, and the buffering hypothesis. Psychological Bulletin, 98(2), 310-357. doi:10.1037/0033-2909.98.2.310

Cummings, E. M., \& Davies, P. T. (2002). Effects of marital conflict on children: Recent advances and emerging themes in process-oriented research. Journal of Child Psychology and Psychiatry, and Allied Disciplines, 43(1), 31-63. doi:10.1111/1469-7610.00003 
El-Sheikh, M., Hinnant, J. B., \& Erath, S. (2011). Developmental trajectories of delinquency symptoms in childhood: The role of marital conflict and autonomic nervous system activity. Journal of Abnormal Psychology, 120(1), 16-32. doi:10.1037/a0020626

Engel, C. C. (2004). Somatization and multiple idiopathic physical symptoms: Relationship to traumatic events and posttraumatic stress disorder. In P. P. Schnurr \& B. L. Green (Eds.), Trauma and heath: Physical health consequences of exposure to extreme stress (pp. 191215). Washington, D.C.: American Psychological Association.

Fagan, P. F., \& Churchill, A. (2012). The effects of divorce on children. Marriage \& Religion Research Institute. Retrieved from http://www.thefamilywatch.org/doc/doc-0283-es.pdf

Frankel, L. A., Umemura, T., Jacobvitz, D., \& Hazen, N. (2015). Marital conflict and parental responses to infant negative emotions: Relations with toddler emotional regulation. Infant Behavior \& Development, 40, 73-83. doi:10.1016/j.infbeh.2015.03.004

Hack, S. M., \& Ramires, V. R. (2010). Adolescência e divórcio parental: Continuidades e rupturas dos relacionamentos [Adolescence and parental divorce: Continuities and relationships ruptures]. Psicologia Clínica, 22(1), 85-97. doi:10.1590/S0103-56652010000100006

Jacquet, S. E., \& Surra, C. A. (2001). Parental divorce and premarital couples: Commitment and other relationship characteristics. Journal of Marriage and Family, 63(3), 635. doi:10.1111/j.1741-3737.2001.00627.x

Kelly, J., \& Emery, R. (2003). Children's adjustment following divorce: Risk and resilience perspectives. Family Relations, 52(4), 352-362. doi:10.1111/j.1741-3729.2003.00352.x

Lansford, J., Malone, P., Castellino, D., Dodge, K., Petit, G., \& Bates, J. (2006). Trajectories of internalizing, externalizing, and grades for children who have and have not experienced their parents' divorce or separation. Journal of Family Psychology, 20(2), 292-301. doi:10.1037/0893-3200.20.2.292

Lovibond, S. H., \& Lovibond, P. F. (1995). Manual for the depression anxiety stress scales. Sydney, NSW: Psychology Foundation of Australia.

Miller, R. S., \& Lefcourt, H. M. (1982). The assessment of social intimacy. Journal of Personality Assessment, 46(5), 514-518. doi:10.1207/s15327752jpa4605_12

Motataianu, I. R. (2015). The relation between anger and emotional synchronization in children from divorced families. Procedia - Social and Behavioral Sciences, 203, 158-162. doi:10.1016/j.sbspro.2015.08.275

Nunes-Costa, R., Lamela, D., \& Figueiredo, B. (2009). Adaptação psicossocial e saúde física em crianças de pais separados [Psychosocial adaptation and physical health in children of separated parents]. Jornal De Pediatria, 85, 385-396. doi:10.2223/JPED.1925

Pais-Ribeiro, J. L., Honrado, A., \& Leal, I. (2004). Contribuição para o estudo da adaptação Portuguesa das Escalas de Ansiedade, Depressão e Stress (EADS) de 21 itens de Lovibond e Lovibond [Contribution to the study of the Portuguese adaptation of the Anxiety, Depression and Stress Scale (EADS) of 21 items of Lovibond and Lovibond]. Psicologia, Saúde \& Doenças, 5(2), 229-239.

Pereira, M. G., \& Araújo-Soares, V. (2002). Perceptions of parents' marital relationship. Research version. Braga, Portugal: University of Minho.

Pereira, M. G., \& Pedras, S. (2008). Physical Symptoms Questionnaire. Research Version. Group Studies on Family Health \& Illness. Braga, Portugal: University of Minho.

Pereira, M. G., \& Pedras, S. (2009). Lifestyle Questionnaire. Research Version. Group Studies on Family Health \& Illness. School of Psychology. Braga, Portugal: University of Minho.

Potter, D. (2010). Psychosocial well-being and the relationship between divorce and children's academic achievement. Journal of Marriage and Family, 72(4), 933-946. doi:10.1111/j.1741-3737.2010.00740.x

Poussin, G., \& Martin-Lebrun, E. (1999). Conséquences de la séparation parentale chez l'enfant [Consequences of parental separation in children]. Paris, France: Eres. 
Proctor, S. P., Heeren, T., White, R. F., Wolfe, J., Borgos, M. S., Davis, J. D., ... Ozonoff, D. (1998). Health status of persian gulf war veterans: Self-reported symptoms, environmental exposures and the effect of stress. International Journal of Epidemiology, 27(6), 1000-1010. doi:10.1093/ije/27.6.1000

Rheingold, A., Acierno, R., \& Resnick, H. (2004). Trauma posttraumatic stress disorder and health risk behaviours. In P. P. Schunrr \& B. L. Green (Eds.), Trauma and health: Physical health consequences of exposure to extreme stress (pp. 217-243). Washington, D.C.: American Psychological Association.

Rhoades, G. K., Stanley, S. M., Markman, H. J., \& Ragan, E. P. (2012). Parents' marital status, conflict, and role modeling: Links with adult romantic relationship quality. Journal of Divorce \& Remarriage, 53, 348-367. doi:10.1080/10502556.2012.675838

Risch, S. C., Jodl, K. M., \& Eccles, J. S. (2004). Role of the father-adolescent relationship in shaping adolescents' attitudes toward divorce. Journal of Marriage and the Family, 66(1), 55-56. doi:10.1111/j.1741-3737.2004.00004.x

Shafer, K., Jensen, T., \& Holmes, E. (2017). Divorce stress, stepfamily stress, and depression among emerging adult stepchildren. Journal of Child and Family Studies, 26(3), 851-862. doi:10.1007/s10826-016-0617-0

Simon, R. W., \& Barrett, A. E. (2010). Nonmarital romantic relationships and mental health in early adulthood: Does the association differ for women and men? Journal of Health and Social Behavior, 51(2), 168-182. doi:10.1177/0022146510372343

Sourander, A., \& Helstelä, L. (2005). Childhood predictors of externalizing and internalizing problems in adolescence: A prospective follow-up study from age 8 to 16. European Child and Adolescent Psychiatry, 14(8), 415-423. doi:10.1007/s00787-005-0475-6

Souza, R. (2000). After daddy and mom divorced: A children's report. Psicologia: Teoria E Pesquisa, 16(3), 203-211.

Steinberg, L. (1987). Impact of puberty on family relations: Effects of pubertal status and pubertal timing. Developmental Psychology, 23(3), 451-460. doi:10.1037/00121649.23.3.451

Storken, I., Roysamb, E., Moum, T., \& Tambs, K. (2005). Adolescents with a childhood experience of parental divorce: A longitudinal study of mental health and adjustment. Journal of Adolescence, 28(6), 725-739. doi:10.1016/j.adolescence.2005.01.001

Thomas, J. R., \& Högnäs, R. S. (2015). The effect of parental divorce on the health of adult children. Longitudinal and Life Course Studies, 6(3), 279-302. doi:10.14301/llcs.v6i3.267

Thormann, N. J. (2000). Como Superar os Efeitos do Divórcio [How to overcome the divorce impact]. Porto Alegre: AGE Editora.

Whitton, S., Rhoades, G. K., Stanley, S. M., \& Markman, H. J. (2008). Effects of parental divorce on marital commitment and confidence. Journal of Family Psychology, 22(5), 791. doi:10.1037/a0012800

Wolchik, S. A., Sandler, I. N., Millsap, R. E., Plummer, B. A., Greene, S. M., \& Anderson, E. R. (2002). Six-year follow-up of preventive interventions for children of divorce: A randomized controlled trial. Journal of the American Medical Association, 288(15), 1874-1881. doi:10.1001/jama.288.15.1874

Yu, T., Petit, G. S., Lansford, J. E., Dodge, K. A., \& Bates, J. (2010). The interactive effects of marital conflict and divorce on parent-adult children's relationships. Journal of Marriage and Family, 72(2), 282-292. doi:10.1111/j.1741-3737.2010.00699.x

Zavaschi, M., Satler, F., Poester, D., Vargas, C., Piazenski, R., Rohde, L., \& Eizirik, C. L. (2002). Associação entre trauma por perda na infância e Depressão na vida adulta [Association between trauma due to loss in childhood and depression in adulthood]. Revista Brasileira De Psiquiatria, 24(4), 189-197. doi:10.1590/S1516-44462002000400009 